\title{
Long-term supplementation with young coconut juice does not prevent bone loss but rather alleviates body weight gain in ovariectomized rats
}

\author{
HIROSHI MATSUSHITA ${ }^{1}$, AKIRA MINAMI ${ }^{2}$, HIROAKI KANAZAWA ${ }^{3}$, TAKASHI SUZUKI ${ }^{2}$, \\ SANAN SUBHADHIRASAKUL ${ }^{4}$, KAZUSHI WATANABE ${ }^{1}$ and AKIHIKO WAKATSUKI ${ }^{1}$
}

\author{
${ }^{1}$ Department of Obstetrics and Gynecology, School of Medicine, Aichi Medical University, Nagakute, Aichi 480-1195; \\ ${ }^{2}$ Department of Biochemistry, School of Pharmaceutical Sciences; ${ }^{3}$ Department of Functional Anatomy, School of Nursing, \\ University of Shizuoka, Shizuoka 422-8526, Japan; ${ }^{4}$ Department of Pharmacognosy and Pharmaceutical Botany, \\ Faculty of Pharmaceutical Sciences, Prince of Songkhla University, Hat-Yai, Songkhla 90110, Thailand
}

Received February 16, 2017; Accepted March 22, 2017

DOI: $10.3892 /$ br.2017.883

\begin{abstract}
Young coconut (Cocos nucifera Linn.) juice (YCJ) has traditionally been consumed to alleviate symptoms associated with the menopause. Recently, the authors demonstrated that short-term (6-week) YCJ supplementation to ovariectomized rats resulted in increased bone mass and bone formation parameter, suggesting that YCJ consumption has a positive effect on bone metabolism and may represent an intervention to help slow the bone loss during menopause transition. The present study sought to determine how long-term (12-week) YCJ supplementation affects bone metabolism in ovariectomized rats, to investigate whether such supplementation may be helpful to in osteoporosis treatment. Ten-week-old female Wistar rats were subjected to either a sham operation (Sham) or bilateral ovariectomy (Ovx). The Ovx+YCJ group received $5 X$-concentrated YCJ at a dose of $15 \mathrm{ml} / \mathrm{kg} /$ day for 12 weeks. Rats in the Ovx group had significantly lower femur bone mineral density than those in the Sham group. YCJ supplementation did not significantly affect this difference. However, YCJ prevented the increase in bone area of the mid third of the femur, a site high in cortical bone, and body weight gain observed following Ovx. Our findings indicate that long-term YCJ intake does not alter bone loss, but rather alleviates body weight gain following menopause.
\end{abstract}

\section{Introduction}

Osteoporosis is a skeletal disorder characterized by compromised bone strength that predisposes affected individuals to

Correspondence to: Dr Hiroshi Matsushita, Department of Obstetrics and Gynecology, School of Medicine, Aichi Medical University, 1-1 Yazakokarimata, Nagakute, Aichi 480-1195, Japan E-mail: hirosm@aichi-med-u.ac.jp

Key words: bone histomorphometry, bone mineral density, coconut, menopause, obesity, osteoporosis an increased risk of fracture. Osteoporosis is more common in women than in men and greatly reduces the healthy life years expectancy, defined as the number of years that a person is expected to live in a healthy condition $(1,2)$. Although osteoporosis is a multifactorial disorder, estrogen deficiency following menopause is strongly associated with rapid bone resorption and loss of bone density (3). Thus, hormone replacement therapy (HRT) has been regarded as one treatment option for the prevention of postmenopausal bone loss $(4,5)$, and some studies have indeed reported that HRT reduces the risk of fractures (6). However, findings from Women's Health Initiative trials revealed that the risks associated with HRT outweighed the benefits, despite the role of HRT in preventing osteoporotic fracture (7-10). Although related societies recommend HRT as a first-line option for the prevention and treatment of osteoporosis in postmenopausal women $<60$ years, there are still many concerns about HRT and the potential risks to various aspects of women's health $(11,12)$.

Alternatives to HRT for the treatment of postmenopausal osteoporosis include bisphosphonates, selective estrogen receptor modulators (SERMs), teriparatide and denosumab (13). However, bisphosphonate alendronate is only effective in osteoporotic women (T-score <-2.5) without previous fractures (14), and the SERM raloxifene fails to show any non-vertebral fracture protection (15). In addition, there is concern about the side effects of gastroesophageal reflux disease, osteonecrosis of the jaw and atypical femoral fractures for alendronate and venous thromboembolism for raloxifene (13). These unfavorable findings associated with pharmaceutical alternatives to HRT have heightened interest in diet and lifestyle changes that can minimize postmenopausal bone loss, and thereby decrease the necessity for drugs in the treatment of osteoporosis.

Cocos nucifera Linn. (Arecaceae), also known as coconut, is widely used in traditional medicine $(16,17)$. Young coconut juice (YCJ), defined as the juice extracted from the fruit of a 6-month-old coconut, is consumed by women in Thailand to alleviate symptoms associated with menopause (18-20), which suggests that YCJ may have phytoestrogenic effects and may 
prevent postmenopausal osteoporosis. The authors demonstrated that short-term (6-week) supplementation with YCJ in ovariectomized rats significantly reduced bone loss, which suggests that YCJ supplementation may mitigate the rapid bone loss observed in women during early menopause (21). In the present study, the effects of long-term (12-week) YCJ supplementation on bone metabolism were examined in ovariectomized rats to investigate whether such supplementation of YCJ could help to prevent postmenopausal osteoporosis.

\section{Materials and methods}

Preparation of YCJ. The composition of YCJ has been reported by Pungmatharith (22) previously. Dried powder of YCJ was prepared as previously described $(18,21)$. Briefly, YCJ obtained from the fruit of $\sim 6$-month-old coconuts was freeze dried and then reconstituted in distilled water, which resulted in $5 \mathrm{X}$-concentrated YCJ. The final solutions were stored at $-20^{\circ} \mathrm{C}$ until use.

Animals and diets. Female Wistar rats (10-weeks-old) were purchased from Japan SLC, Inc. (Hamamatsu, Japan). Upon arrival, they were housed in a temperature $\left(23 \pm 1^{\circ} \mathrm{C}\right)$ - and humidity $(55 \pm 5 \%)$-controlled room under a $12 \mathrm{~h}$ light-dark cycle and fed standard rodent chow and water ad libitum. Following acclimatization for 2 weeks, the rats were randomly divided into four groups (Baseline, $\mathrm{n}=5$ rats; Sham, Ovx, and $\mathrm{Ovx}+\mathrm{YCJ}$ groups, $\mathrm{n}=10$ rats per group). The rats in the baseline group were anesthetized by intraperitoneal injection of $10 \%$ chloral hydrate $(400 \mathrm{mg} / \mathrm{kg}$ body weight), and immediately sacrificed by cardiac puncture. This group provided reference values for skeletal measurements, which enabled the determination of changes in skeletal tissue resulting from surgery and aging (23). The rats in the remaining three groups were anesthetized and subjected either to sham operation (Sham group) or bilateral ovariectomy (Ovx and Ovx+YCJ groups) using the dorsal approach. At 2 days following surgery, $5 \mathrm{X}$ YCJ was administered by gavage to rats in the Ovx+YCJ group at a daily dose of $15 \mathrm{ml} / \mathrm{kg}$ body weight (equivalent to $75 \mathrm{ml} / \mathrm{kg}$ body weight of $1 \mathrm{X}$ YCJ) for 12 weeks. The dose of YCJ was determined as previously described $(18,21)$. The rats in the other groups were administered tap water by gavage daily for 12 weeks. At 12 weeks following surgery, the rats in all three groups were anesthetized and sacrificed by cardiac puncture. The rats were given intraperitoneal injections of the fluorochrome markers calcein (Sigma-Aldrich; Merck KGaA, Darmstadt, Germany; $10 \mathrm{mg} / \mathrm{kg}$ body weight) and tetracycline-HCl (Sigma-Aldrich; Merck KGaA; 25 mg/kg body weight) 5 and 2 days prior to necropsy, respectively, to evaluate the bone dynamics by histomorphometry. At necropsy, the uterus was resected and weighed to determine whether the Ovx was successful. Blood was collected by cardiac puncture; serum was obtained and stored at $-80^{\circ} \mathrm{C}$ until analysis by ELISA. The right femurs were wrapped in a saline-soaked gauze and stored at $-20^{\circ} \mathrm{C}$ for subsequent densitometry. The left femurs were cleaned of soft tissue and fixed in $70 \%$ ethanol for bone histomorphometry. The present study was conducted in parallel with a previous study of the authors (24) in order to minimize the number of control rats that were sacrificed (Baseline, Sham and Ovx groups). The experimental protocol was approved by the Animal Ethics Committee of the University of Shizuoka (Shizuoka, Japan).

Bone densitometry. The right femurs were completely thawed at room temperature, and the bone mineral density (BMD) was measured by dual-energy X-ray absorptiometry (DXA) and analyzed using small animal software (version 12.5; QDR-4500A; Hologic, Inc., Bedford, MA, USA). The BMD was calculated as the bone mineral content (BMC) divided by the bone area (BA). In addition, the BA, BMC and BMD in the proximal, mid diaphyseal and distal parts of the femur were determined by dividing the femur into three equal parts according to length. The coefficients of variation for the scans and standards were $<1.0 \%$.

Peripheral quantitative computed tomography ( $p Q C T)$. The right femurs were placed in a polypropylene tube filled with saline solution and scanned using pQCT (XCT Research $\mathrm{SA}+$; Stratec Medizintechnik GmbH, Pforzheim, Germany) at a voxel size of $0.12 \mathrm{~mm}$. The scan line was adjusted using scout view, and transverse sections were recorded at the distal femoral metaphysis ( $3 \mathrm{~mm}$ proximal to the distal growth plate) and the midshaft ( $50 \%$ bone length). Images were analyzed using XCT software (version 6.20; Stratec Medizintechnik $\mathrm{GmbH}$ ) in contour mode 2 and peel mode 2 (threshold $395 \mathrm{mg} / \mathrm{cm}^{3}$ ) to calculate the trabecular and total bone parameters at the metaphysis and in cortical mode 1 (threshold $690 \mathrm{mg} / \mathrm{cm}^{3}$ ) to calculate the cortical bone parameters at the diaphysis. The following parameters were measured at the femoral metaphysis: Total BMC (T.BMC; mg), total BMD (T.BMD; $\mathrm{mg} / \mathrm{cm}^{3}$ ), total cross-sectional area (CSA) (T.CSA; $\mathrm{mm}^{2}$ ), trabecular BMC (Tb.BMC; mg), trabecular BMD (Tb. BMD; $\mathrm{mg} / \mathrm{cm}^{3}$ ), and trabecular CSA (Tb.CSA; $\left.\mathrm{mm}^{2}\right)$. At the midshaft, the cortical BMC (Ct.BMC; mg), cortical BMD (Ct BMD; $\left.\mathrm{mg} / \mathrm{cm}^{3}\right)$, cortical CSA (Ct.CSA; $\left.\mathrm{mm}^{2}\right)$, cortical thickness (Ct.Th; mm), periosteal circumference (Peri.C; mm) and endosteal circumference (Endo.C; $\mathrm{mm}$ ) were evaluated.

Bone histomorphometry. The left femurs were stained with Villanueva bone stain (Maruto Instrument Co., Ltd., Tokyo, Japan) for 7 days prior to dehydration in a graded series of ethanol and embedded without decalcification in methyl methacrylate (Wako Pure Chemical Industries, Ltd., Osaka, Japan). Frontal sections $(5 \mu \mathrm{m})$ of the distal femur were cut using a microtome (RM2255; Leica Microsystems GmbH, Wetzlar, Germany) and mounted on slides. The specimens were examined under a fluorescence microscope (BX53; Nikon Corporation, Tokyo, Japan). The structural and dynamic histomorphometric indices were measured in the cancellous bone at the secondary spongiosa located $500 \mu \mathrm{m}$ from the epiphyseal growth plate and $250 \mu \mathrm{m}$ from the endocortical surface using a semi-automatic image analysis system (Histometry RT CAMERA; System Supply Co., Ltd., Ina, Japan) at a magnification of $x 320$. The histomorphometric nomenclature used in the present study is in accordance with the report of the American Society for Bone and Mineral Research Histomorphometry Nomenclature Committee (25). Bone section preparations and histomorphometric measurements were performed at the Niigata Bone Science Institute (Niigata, Japan). 
Serum bone turnover markers. Osteocalcin (OC) and RatLaps (bone-related degeneration from C-terminal telopeptides of type I collagen) were determined in order to evaluate bone formation and resorption status, respectively. OC (Rat-MID Osteocalcin EIA; Immunodiagnostics Systems Holdings PLC, Tyne \& Wear, UK; cat no. AC-12F1) and RatLaps (RatLaps EIA; Immunodiagnostics Systems Holdings PLC; cat. no. AC-06F1) was measured using an ELISA following protocols provided by the manufacturer.

Statistical analyses. The data are presented as the mean \pm standard error of the mean, and data management and statistical analyses were performed with JMP 9.0.2 (SAS Institute Inc., Cary, NC, USA). The specific effects of Ovx and YCJ supplementation were examined by comparing values of the Sham, Ovx and Ovx $+\mathrm{YCJ}$ groups using analysis of variance and analysis of covariance with body weight as the covariate $(26,27)$, with Tukey's honest significant difference (HSD) test. $\mathrm{P}<0.05$ was considered to indicate a statistically significant difference.

\section{Results}

Effects of YCJ on body and uterine weights. There were early increases in the body weight of rats in the Ovx group, with significant differences between the Ovx and $\mathrm{Ovx}+\mathrm{YCJ}$ groups during the experimental period. At the end of the study, the Ovx group had a significantly greater body weight than the Ovx+YCJ group and tended to have a greater body weight than the Sham group. There was no significant difference in body weight between the Sham and Ovx+YCJ groups (Fig. 1). The rats in the Ovx group had a significantly lower mean uterine weight than those in the Sham group, suggesting that the Ovx procedure was successful. There were no significant differences in uterine weight between the $\mathrm{Ovx}$ and $\mathrm{Ovx}+\mathrm{YCJ}$ groups (data not shown).

DXA of the femur. The right femoral BMD of the rats in the Ovx group was significantly lower than that of the rats in the Sham group. The BMD of the rats in the Ovx+YCJ group was not significantly different from that of the rats in the Ovx group. When the femur was divided into three segments of equal length, there were significant differences in the BMD and BMC between the Sham and Ovx groups at the proximal and distal ends of the femur, sites that are high in cancellous bone, but not at the mid diaphysis, a site that is high in cortical bone. The rats supplemented with YCJ (Ovx+YCJ group) presented no significant differences in the $\mathrm{BMC}$ or $\mathrm{BMD}$ of the right femur compared with the rats in the Ovx group, regardless of the femur site (i.e., proximal, diaphyseal and distal sites; Table I). The BA at the mid diaphysis was significantly greater in the Ovx group than in the Sham group, whereas there was no difference in the mid diaphyseal BA between the Sham and Ovx+YCJ groups.

$p Q C T$ of the femur metaphysis and diaphysis. The Tb.BMC of the distal metaphysis was significantly higher in the Ovx group than in the Sham group. However, due to a significant increase in the Tb.CSA, the Tb.BMD in the Ovx group was significantly lower than that in the Sham group. There were no significant differences in the parameters between the

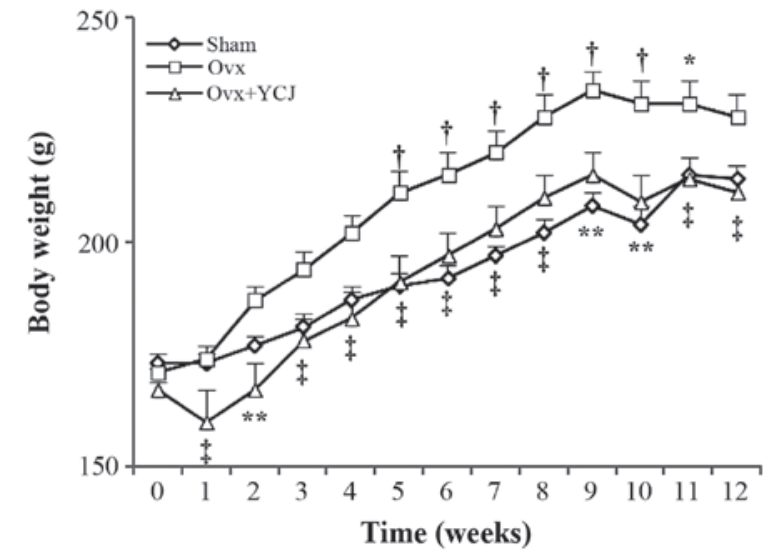

Figure 1. Mean body weight change of sham-operated (Sham) and ovariectomized rats supplemented with $(\mathrm{Ovx}+\mathrm{YCJ})$ or without $(\mathrm{Ovx}) \mathrm{YCJ}$ for 12 weeks ( $n=10$ /group). The values represent the mean \pm standard error of the mean. ${ }^{*} \mathrm{P}<0.05,{ }^{\dagger} \mathrm{P}<0.01$ vs. Sham; ${ }^{\star} \mathrm{P}<0.05,{ }^{* *} \mathrm{P}<0.01$ vs. Ovx (Sham vs. Ovx vs. Ovx $+Y C J$, analysis of variance with Tukey's honest significant difference test). YCJ, young coconut juice; Ovx, bilateral ovariectomy.

Sham and Ovx groups at the diaphysis. YCJ supplementation induced no significant differences in any parameter evaluated by pQCT at the diaphyseal and distal sites (Table II).

Bone histomorphometry. The histomorphometric indices for distal femoral metaphyseal cancellous bone are summarized in Table III. The bone volume and trabecular number were significantly lower in the Ovx group than in the Sham group, whereas the osteoid volume and osteoid surface were higher in the Ovx group than in the Sham group. Regarding the dynamic indices, a larger mineralized surface was found in the Ovx group than in the Sham group. However, these differences were not significantly affected by long-term YCJ supplementation.

Serum bone turnover markers. The serum OC level was significantly lower in rats in the Ovx+YCJ group than in those in the Sham and Ovx groups, which suggests that YCJ supplementation suppressed bone formation. On the other hand, the serum bone resorption marker RatLaps was not affected by YCJ supplementation (Fig. 2).

\section{Discussion}

It was recently reported that ovariectomized rats supplemented with YCJ for a short term (6 weeks) demonstrated a significantly higher femoral BMD (as measured by DXA) and higher bone formation rates (as measured by trabecular bone histomorphometry) than rats that did not receive YCJ (21), which suggests that YCJ may mitigate the rapid bone loss observed in women during early menopause. In the present study, the effects of long-term (12-week) YCJ supplementation on bone metabolism was examined in ovariectomized rats to investigate whether YCJ could help prevent the development of postmenopausal osteoporosis. However, the present study demonstrated that ovariectomized rats with longer-term (12 weeks) YCJ supplementation (Ovx+YCJ group) had a BMD similar to that of rats without YCJ supplementation (Ovx group). 
Table I. Femur BMC and BMD in sham-operated (Sham) and ovariectomized rats supplemented with (Ovx+YCJ) or without (Ovx) YCJ for 12 weeks.

\begin{tabular}{|c|c|c|c|c|}
\hline \multirow[b]{2}{*}{ Parameters } & \multirow{2}{*}{$\frac{0 \text { weeks }}{\text { Baseline }(n=5)}$} & \multicolumn{3}{|c|}{12 weeks } \\
\hline & & Sham $(n=8)$ & Ovx $(n=8)$ & $\mathrm{Ovx}+\mathrm{YCJ}(\mathrm{n}=8)$ \\
\hline \multicolumn{5}{|c|}{ Femur BMC (g) } \\
\hline Whole & $0.215 \pm 0.004$ & $0.298 \pm 0.004$ & $0.292 \pm 0.009$ & $0.276 \pm 0.007^{\mathrm{a}}$ \\
\hline Proximal & $0.081 \pm 0.003$ & $0.113 \pm 0.003$ & $0.108 \pm 0.004^{\mathrm{a}}$ & $0.103 \pm 0.003^{\mathrm{a}}$ \\
\hline Mid & $0.050 \pm 0.003$ & $0.070 \pm 0.002$ & $0.077 \pm 0.004$ & $0.073 \pm 0.003$ \\
\hline Distal & $0.087 \pm 0.001$ & $0.119 \pm 0.002$ & $0.112 \pm 0.003^{\mathrm{a}}$ & $0.104 \pm 0.003^{\mathrm{b}}$ \\
\hline \multicolumn{5}{|c|}{ Femur BA $\left(\mathrm{cm}^{2}\right)$} \\
\hline Whole & $1.220 \pm 0.010$ & $1.457 \pm 0.017$ & $1.535 \pm 0.032$ & $1.450 \pm 0.017$ \\
\hline Proximal & $0.443 \pm 0.010$ & $0.542 \pm 0.009$ & $0.563 \pm 0.011$ & $0.536 \pm 0.010$ \\
\hline Mid & $0.340 \pm 0.006$ & $0.396 \pm 0.004$ & $0.435 \pm 0.012^{\mathrm{a}}$ & $0.409 \pm 0.005$ \\
\hline Distal & $0.458 \pm 0.004$ & $0.542 \pm 0.009$ & $0.563 \pm 0.011$ & $0.527 \pm 0.011$ \\
\hline \multicolumn{5}{|c|}{ Femur BMD $\left(\mathrm{g} / \mathrm{cm}^{2}\right)$} \\
\hline Whole & $0.176 \pm 0.002$ & $0.204 \pm 0.002$ & $0.190 \pm 0.003^{\mathrm{b}}$ & $0.190 \pm 0.003^{\mathrm{b}}$ \\
\hline Proximal & $0.183 \pm 0.002$ & $0.209 \pm 0.002$ & $0.192 \pm 0.003^{\mathrm{b}}$ & $0.192 \pm 0.004^{\mathrm{b}}$ \\
\hline Mid & $0.146 \pm 0.006$ & $0.177 \pm 0.007$ & $0.176 \pm 0.007$ & $0.178 \pm 0.006$ \\
\hline Distal & $0.190 \pm 0.004$ & $0.219 \pm 0.002$ & $0.198 \pm 0.003^{\mathrm{b}}$ & $0.198 \pm 0.004^{\mathrm{b}}$ \\
\hline
\end{tabular}

Data are presented as the mean \pm standard error of the mean. ${ }^{\mathrm{a}} \mathrm{P}<0.05,{ }^{\mathrm{b}} \mathrm{P}<0.01 \mathrm{vs}$. Sham. BMD, bone mineral content; BMD, bone mineral density.

Table II. Trabecular and cortical parameters determined by peripheral quantitative computed tomography in sham-operated (Sham) and ovariectomized rats supplemented with (Ovx+YCJ) or without (Ovx) YCJ for 12 weeks.

\begin{tabular}{|c|c|c|c|c|}
\hline \multirow[b]{2}{*}{ Parameters } & \multirow{2}{*}{$\frac{0 \text { weeks }}{\text { Baseline }(n=5)}$} & \multicolumn{3}{|c|}{12 weeks } \\
\hline & & Sham $(n=8)$ & Ovx $(n=8)$ & $\mathrm{Ovx}+\mathrm{YCJ}(\mathrm{n}=8)$ \\
\hline \multicolumn{5}{|l|}{ Distal metaphysis } \\
\hline T.BMC (mg) & $8.72 \pm 0.32$ & $9.85 \pm 0.29$ & $8.72 \pm 0.22^{\mathrm{b}}$ & $8.37 \pm 0.28^{\mathrm{b}}$ \\
\hline T.BMD $\left(\mathrm{mg} / \mathrm{cm}^{3}\right)$ & $611 \pm 14$ & $658 \pm 11$ & $540 \pm 8^{\mathrm{b}}$ & $538 \pm 11^{\mathrm{b}}$ \\
\hline T.CSA $\left(\mathrm{mm}^{2}\right)$ & $14.3 \pm 0.3$ & $15.0 \pm 0.3$ & $16.2 \pm 0.5$ & $15.5 \pm 0.3$ \\
\hline Tb.BMC (mg) & $0.774 \pm 0.160$ & $0.815 \pm 0.042$ & $1.129 \pm 0.046^{\mathrm{b}}$ & $1.050 \pm 0.072^{\mathrm{a}}$ \\
\hline Tb.BMD $\left(\mathrm{mg} / \mathrm{cm}^{3}\right)$ & $304 \pm 16$ & $253 \pm 8$ & $177 \pm 5^{\mathrm{b}}$ & $167 \pm 5^{\mathrm{b}}$ \\
\hline $\operatorname{Tb} . \mathrm{CSA}\left(\mathrm{mm}^{2}\right)$ & $2.65 \pm 0.58$ & $3.26 \pm 0.25$ & $6.40 \pm 0.27^{b}$ & $6.30 \pm 0.43^{b}$ \\
\hline \multicolumn{5}{|l|}{ Diaphysis } \\
\hline Ct.BMC (mg) & $4.55 \pm 0.04$ & $5.91 \pm 0.06$ & $6.05 \pm 0.13$ & $5.82 \pm 0.10$ \\
\hline Ct.BMD $\left(\mathrm{mg} / \mathrm{cm}^{3}\right)$ & $1230 \pm 5$ & $1320 \pm 3$ & $1310 \pm 4$ & $1310 \pm 4$ \\
\hline Ct.CSA $\left(\mathrm{mm}^{2}\right)$ & $3.69 \pm 0.04$ & $4.48 \pm 0.04$ & $4.63 \pm 0.10$ & $4.45 \pm 0.07$ \\
\hline Ct.Th (mm) & $0.494 \pm 0.010$ & $0.598 \pm 0.004$ & $0.594 \pm 0.006$ & $0.586 \pm 0.009$ \\
\hline Peri.C (mm) & $9.04 \pm 0.08$ & $9.38 \pm 0.07$ & $9.66 \pm 0.15$ & $9.44 \pm 0.08$ \\
\hline Endo.C (mm) & $5.94 \pm 0.13$ & $5.63 \pm 0.08$ & $5.93 \pm 0.15$ & $5.76 \pm 0.10$ \\
\hline
\end{tabular}

Data are presented as the mean \pm standard error of the mean. ${ }^{a} \mathrm{P}<0.05,{ }^{b} \mathrm{P}<0.01$ vs. Sham. Tb, trabecular; $\mathrm{T}$, total; $\mathrm{Ct}$, cortical; $\mathrm{BMC}$, bone mineral content; BMD, bone mineral density; CSA, cross-sectional area; Th, thickness; Peri.C, periosteal circumference; Endo.C, endosteal circumference.

It is unknown why the results of the present investigation failed to corroborate the findings of the prior study of the authors, in which trabecular bone histomorphometry revealed that short-term (6-week) supplementation of YCJ accelerated the parameters of bone formation without affecting bone resorption parameters in ovariectomized rats. In addition to its use in 
Table III. Dynamic cancellous bone indices in the distal femoral metaphysis in sham-operated (Sham) and ovariectomized rats supplemented with $(\mathrm{Ovx}+\mathrm{YCJ})$ or without (Ovx) YCJ for 12 weeks.

0 weeks

Parameters

Static indices

Bone volume (\%)

Trabecular thickness $(\mu \mathrm{m})$

Trabecular number $(\mathrm{N} / \mathrm{mm})$

Osteoid volume (\%)

Osteoid surface (\%)

Osteoblast surface (\%)

Dynamic indices

Mineralizing surface $(\%)$

Mineral apposition rate $(\mu \mathrm{m} /$ day $)$

Bone formation rate $\left(\mathrm{mm}^{3} / \mathrm{mm}^{2} /\right.$ year $)$

Bone formation rate (\%/year)
Baseline (n=5)

$28.5 \pm 1.2$
$55.4 \pm 1.0$
$5.15 \pm 0.20$
$4.09 \pm 0.44$
$26.2 \pm 2.4$
$13.39 \pm 2.21$

$33.1 \pm 1.5$

$2.50 \pm 0.17$

$0.302 \pm 0.023$

$1,100 \pm 97$

12 weeks

\begin{tabular}{lll}
\hline Sham $(n=8)$ & Ovx $(n=8)$ & Ovx + YCJ $(n=8)$
\end{tabular}

$28.8 \pm 1.3$
$62.0 \pm 1.5$
$4.63 \pm 0.17$
$2.03 \pm 0.23$
$15.7 \pm 1.4$
$3.97 \pm 0.54$

$17.7 \pm 2.1$

$1.27 \pm 0.05$

$0.081 \pm 0.010$

$261 \pm 35$

$15.0 \pm 0.9^{\mathrm{b}}$
$64.2 \pm 2.2$
$2.34 \pm 0.12^{\mathrm{b}}$
$4.36 \pm 0.61^{\mathrm{a}}$
$32.8 \pm 2.5^{\mathrm{b}}$
$7.34 \pm 1.23$

$31.9 \pm 2.4^{\mathrm{b}}$

$1.45 \pm 0.10$

$0.173 \pm 0.023$

$536 \pm 73$
$14.6 \pm 2.5^{\mathrm{b}}$

$64.9 \pm 3.5$

$2.18 \pm 0.23^{\mathrm{b}}$

$4.37 \pm 0.46^{\mathrm{b}}$

$33.6 \pm 2.4^{\mathrm{b}}$

$8.54 \pm 2.22$

$25.9 \pm 1.8^{\mathrm{a}}$

$1.42 \pm 0.06$

$0.135 \pm 0.012^{\mathrm{a}}$

$414 \pm 29$

Data are presented as the mean \pm standard error of the mean. ${ }^{a} \mathrm{P}<0.05,{ }^{\mathrm{b}} \mathrm{P}<0.01$ vs. Sham.

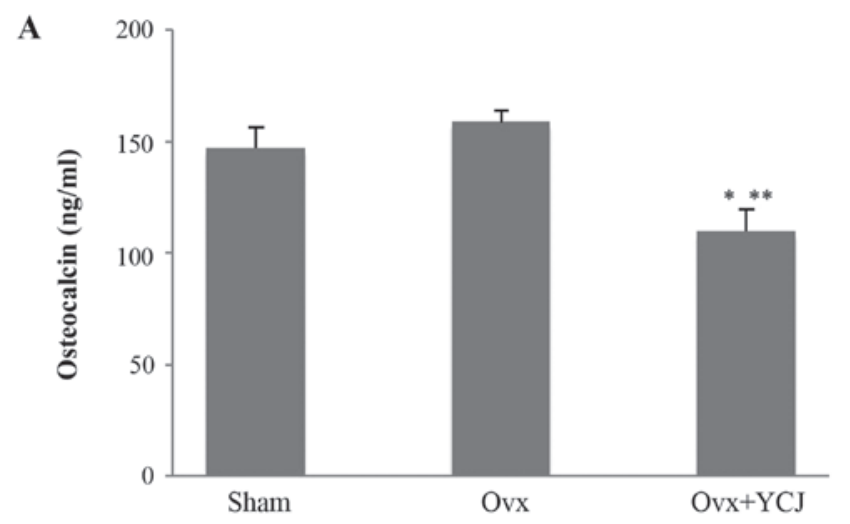

B

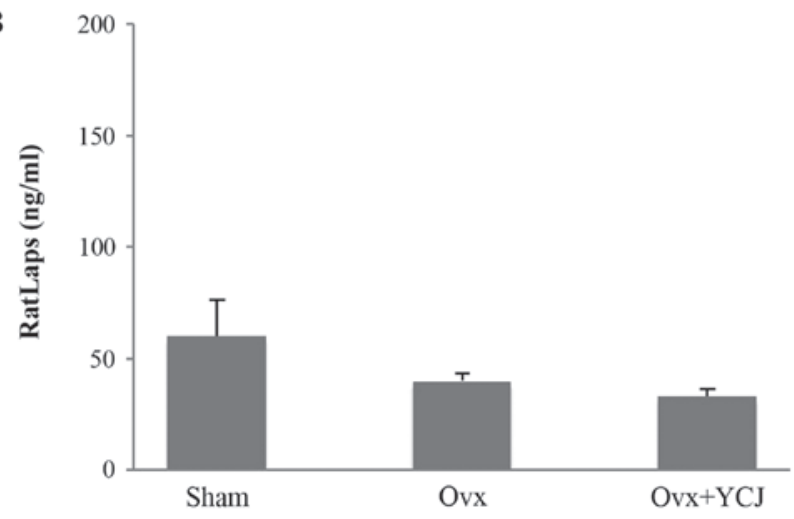

Figure 2. (A) Serum osteocalcin and (B) RatLaps in the sham-operated (Sham) and ovariectomized rats supplemented with $(\mathrm{Ovx}+\mathrm{YCJ})$ or without (Ovx) YCJ for 12 weeks. The values represent the mean \pm standard error of the mean. ${ }^{*} \mathrm{P}<0.05$ vs. Sham; ${ }^{* *} \mathrm{P}<0.01$ vs. Ovx (Sham vs. Ovx vs. Ovx $+\mathrm{YCJ}$, analysis of covariance adjusted for body weight with Tukey's honest significant difference test). YCJ, young coconut juice; Ovx, bilateral ovariectomy.

alleviating menopausal symptoms, coconut juice has also been used as a temporary contraceptive in Thailand and Indonesia.
In contrast, women in these areas are prohibited from drinking coconut juice because it disrupts their menstrual cycle, and individuals in Java are afraid to drink coconut milk because it may diminish their fertility (18-20). It therefore seems that YCJ may exert its bone protective effects only in the presence of endogenous sex steroids, suggesting that the positive effect on bone observed 6 weeks following ovariectomy (21) were no longer apparent at 12 weeks following ovariectomy.

Although we have still not identified the exact constituents in YCJ that prevented bone loss following Ovx in the previous study, YCJ contains estrogens (e.g., 17 $\beta$-estradiol, estrone and estrone-3-glucuronide), testosterone and various phytoestrogens (22). All of these constituents may have positively affected bone parameters in the authors' previous study. It is important to note that $17 \beta$-estradiol exerts its bone-protective effects by suppressing both bone formation and resorption, with a greater emphasis on the latter $(28,29)$. It has been speculated that the effect of YCJ supplementation on bone may differ from that of estradiol. Ovariectomy in young, growing rodents decreases BMD of the trabecular bone and increases radial growth of the cortical bone, and both of these effects can be reversed by estrogen (30). Estrogen exerts many of its effects via two nuclear estrogen receptors (ERs), ER $\alpha$ and ER $\beta$. Although both receptors have been detected in all skeletal cell types, for example chondrocytes, bone marrow stromal cells, osteoblasts, osteocytes and osteoclasts and their progenitor cells, the vast majority of the estrogen bone-sparing effects are mediated by ER $\alpha$ in both the cortical and cancellous bone compartments $(31,32)$. By contrast, ER $\beta$ may not serve a major role in bone, with the possible exception that it may exert an inhibitory effect on periosteal apposition $(30,31)$. In the present study, DXA measurements demonstrated that the BA at the mid diaphysis, a site that is high in cortical bone, was significantly greater in the Ovx group than in the Sham group, whereas there was no difference in the mid diaphyseal BA 
between the Sham and Ovx+YCJ groups. YCJ contains various phytoestrogens, such as $\beta$-sitosterol (58\% of the total composition of $1 \mathrm{ml} \mathrm{YCJ}$ ), stigmastatrienol, stigmasterol, fucosterol and $\alpha$-spinasterol (22). Phytoestrogens are plant derivatives that behave differently from estrogen but similarly to SERMs with a higher affinity for ER $\beta$ (33). The serum bone formation marker OC was significantly lower in rats in the Ovx+YCJ group than in those in the Ovx group. However, bone histomorphometry indicated that trabecular bone formation was not affected by YCJ supplementation. Thus, the authors speculate that long-term supplementation with YCJ may prevent the periosteal apposition of cortical bone, possibly via ER $\beta$.

Unexpectedly, long-term supplementation with YCJ $(\mathrm{Ovx}+\mathrm{YCJ})$ resulted in a significantly lower body weight compared to no supplementation. Ovariectomized animals present body weight gain and excessive feeding. The treatment of ovariectomized animals with estrogen prevents these changes, and these effects are mediated, in large part, through $\mathrm{ER} \alpha(34,35)$. The present study demonstrated that the uterine weight of the rats that were administered YCJ at a dose equivalent to $75 \mathrm{ml} / \mathrm{kg} /$ day was not significantly different from that of the rats that were not administered YCJ. Punghmatharith (22) reported that $17 \beta$-estradiol was present in YCJ at $2.45 \mathrm{pg} / \mathrm{ml}$ and that the subcutaneous injection of an ethereal extract of YCJ at a dose equivalent to $7,500 \mathrm{ml} / \mathrm{kg} /$ day for 3 consecutive days significantly increased the uterine wet weight of immature rats; however, this effect was not seen when YCJ was injected at $4,000 \mathrm{ml} / \mathrm{kg} / \mathrm{day}$ (22). Thus, the dose of $17 \beta$-estradiol in YCJ is small, suggesting that YCJ may alleviate body weight gain following Ovx in rats through mechanisms different from those of ER $\alpha$. However, some recent transgenic studies have indicated that ER $\beta$ may serve a key role in preventing obesity and obesity-related metabolic disease (36,37). Radenahmad et al (20) demonstrated that both ER $\alpha$ and ER $\beta$ were highly expressed in a cutaneous wound of ovariectomized rats supplemented with YCJ, although ER $\alpha$ is predominantly expressed in normal skin. These findings may endorse the authors' speculation that the effects of YCJ may be exerted through ER $\beta$.

In conclusion, long-term supplementation with YCJ did not improve indices of bone mass or bone histomorphometry in ovariectomized rats, arguing against the benefits of YCJ in preventing osteoporosis in postmenopausal women. Although accumulated evidence suggests that consuming a phytoestrogen-rich diet alleviates symptoms associated with menopause, studies into the direct effects of dietary phytoestrogens on bone in postmenopausal women are extremely limited (38). Thus, physicians should not hesitate to initiate drug treatment in women at risk of osteoporosis and fracture, even if patients prefer diet and lifestyle alterations. Nevertheless, considering the results of our previous study (21), YCJ may be beneficial in mitigating bone loss in women during early menopause, which may delay the start and reduce the total duration of anti-osteoporotic drug therapy. In addition, YCJ consumption may help to prevent body weight gain following menopause.

\section{Acknowledgements}

The present study was supported, in part, by a JMS Bayer Schering Pharma Grant from the Japan Menopause Society (to H.M.) and a Scientific Research Grant from the Amano Foundation of Industrial Technology (to A.M.).

\section{References}

1. Daan NM and Fauser BC: Menopause prediction and potential implications. Maturitas 82: 257-265, 2015.

2. Salomon JA, Wang H, Freeman MK, Vos T, Flaxman AD, Lopez AD and Murray CJ: Healthy life expectancy for 187 countries, 1990-2010: A systematic analysis for the Global Burden Disease Study 2010. Lancet 380: 2144-2162, 2012.

3. Raisz LG: Pathogenesis of osteoporosis: Concepts, conflicts, and prospects. J Clin Invest 115: 3318-3325, 2005.

4. Wells G, Tugwell P, Shea B, Guyatt G, Peterson J, Zytaruk N, Robinson V, Henry D, O'Connell D and Cranney A; Osteoporosis Methodology Group and The Osteoporosis Research Advisory Group: Meta-analyses of therapies for postmenopausal osteoporosis. V. Meta-analysis of the efficacy of hormone replacement therapy in treating and preventing osteoporosis in postmenopausal women. Endocr Rev 23: 529-539, 2002.

5. Dören M, Nilsson JA and Johnell O: Effects of specific post-menopausal hormone therapies on bone mineral density in post-menopausal women: A meta-analysis. Hum Reprod 18: 1737-1746, 2003

6. Torgerson DJ and Bell-Syer SE: Hormone replacement therapy and prevention of nonvertebral fractures: A meta-analysis of randomized trials. JAMA 285: 2891-2897, 2001.

7. Rossouw JE, Anderson GL, Prentice RL, LaCroix AZ, Kooperberg C, Stefanick ML, Jackson RD, Beresford SA, Howard BV, Johnson KC, et al; Writing Group for the Women's Health Initiative Investigators: Risks and benefits of estrogen plus progestin in healthy postmenopausal women: Principal results From the Women's Health Initiative randomized controlled trial. JAMA 288: 321-333, 2002.

8. Cauley JA, Robbins J, Chen Z, Cummings SR, Jackson RD, LaCroix AZ, LeBoff M, Lewis CE, McGowan J, Neuner J, et al; Women's Health Initiative Investigators: Effects of estrogen plus progestin on risk of fracture and bone mineral density: The Women's Health Initiative randomized trial. JAMA 290: 1729-1738, 2003.

9. Anderson GL, Limacher M, Assaf AR, Bassford T, Beresford SA, Black H, Bonds D, Brunner R, Brzyski R, Caan B, et al; Women's Health Initiative Steering Committee: Effects of conjugated equine estrogen in postmenopausal women with hysterectomy: The Women's Health Initiative randomized controlled trial. JAMA 291: 1701-1712, 2004.

10. Jackson RD, Wactawski-Wende J, LaCroix AZ, Pettinger M, Yood RA, Watts NB, Robbins JA, Lewis CE, Beresford SA, Ko MG, et al; Women's Health Initiative Investigators: Effects of conjugated equine estrogen on risk of fractures and BMD in postmenopausal women with hysterectomy: Results from the women's health initiative randomized trial. J Bone Miner Res 21: 817-828, 2006.

11. O'Brien J, Jackson JW, Grodstein F, Blacker D and Weuve J: Postmenopausal hormone therapy is not associated with risk of all-cause dementia and Alzheimer's disease. Epidemiol Rev 36: 83-103, 2014.

12. Beral V, Gaitskell K, Hermon C, Moser K, Reeves G and Peto R; Collaborative Group On Epidemiological Studies Of Ovarian Cancer: Menopausal hormone use and ovarian cancer risk: Individual participant meta-analysis of 52 epidemiological studies. Lancet 385: 1835-1842, 2015.

13. O'Connor KM: Evaluation and treatment of osteoporosis. Med Clin North Am 100: 807-826, 2016.

14. Cummings SR, Black DM, Thompson DE, Applegate WB, Barrett-Connor E, Musliner TA, Palermo L, Prineas R, Rubin SM, Scott JC, et al: Effect of alendronate on risk of fracture in women with low bone density but without vertebral fractures: Results from the Fracture Intervention Trial. JAMA 280: 2077-2082, 1998.

15. Ettinger B, Black DM, Mitlak BH, Knickerbocker RK, Nickelsen T, Genant HK, Christiansen C, Delmas PD, Zanchetta JR, Stakkestad J, et al; Multiple Outcomes of Raloxifene Evaluation (MORE) Investigators: Reduction of vertebral fracture risk in postmenopausal women with osteoporosis treated with raloxifene: Results from a 3-year randomized clinical trial. JAMA 282: 637-645, 1999.

16. DebMandal M and Mandal S: Coconut (Cocos nucifera L.: Arecaceae): in health promotion and disease prevention. Asian Pac J Trop Med 4: 241-247, 2011. 
17. Dua K, Sheshala R, Ling TY, Hui Ling S and Gorajana A: Anti-inflammatory, antibacterial and analgesic potential of cocos nucifera linn.: A review. Antiinflamm Antiallergy Agents Med Chem 12: 158-164, 2013.

18. Radenahmad N, Vongvatcharanon U, Withyachumnarnkul B and Connor RJ: Serum levels of $17 \beta$-estradiol in ovariectomized rats fed young-coconut juice and its effect on wound healing. Songklanakarin J Sci Technol 28: 897-910, 2006.

19. Radenahmad N, Saleh F, Sawangjaroen K, Rundorn W, Withyachumnarnkul B and Connor JR: Young coconut juice significantly reduces histopathological changes in the brain that are induced by hormonal imbalance: A possible implication to postmenopausal women. Histol Histopathol 24: 667-674, 2009.

20. Radenahmad N, Saleh F, Sayoh I, Sawangjaroen K, Subhadhirasakul P, Boonyoung P, Rundorn W and Mitranun W: Young coconut juice can accelerate the healing process of cutaneous wounds. BMC Complement Altern Med 12: 252, 2012.

21. Morii Y, Matsushita H, Minami A, Kanazawa H, Suzuki T, Subhadhirasakul S, Watanabe K and Wakatsuki A: Young coconut juice supplementation results in greater bone mass and bone formation indices in ovariectomized rats: A preliminary study. Phytother Res 29: 1950-1955, 2015.

22. Pungmatharith B: Sex hormone-like substances in young coconut juice and their effects on uterine growth in rats. Songklanakarin J Sci Technol 10: 221-226, 1988.

23. Kalu DN: The ovariectomized rat model of postmenopausal bone loss. Bone Miner 15: 175-191, 1991.

24. Ohyama Y, Matsushita H, Minami A, Kanazawa H, Suzuki T, Watanabe $\mathrm{K}$ and Wakatsuki A: Effect of the ethanol extract of Pleurotus eryngii on bone metabolism in ovariectomized rats. Climacteric 17: 492-499, 2014

25. Dempster DW, Compston JE, Drezner MK, Glorieux FH Kanis JA, Malluche H, Meunier PJ, Ott SM, Recker RR and Parfitt AM: Standardized nomenclature, symbols, and units for bone histomorphometry: A 2012 update of the report of the ASBMR Histomorphometry Nomenclature Committee. J Bone Miner Res 28: 2-17, 2013.

26. Lane MA, Black A, Handy AM, Shapses SA, Tilmont EM, Kiefer TL, Ingram DK and Roth GS: Energy restriction does not alter bone mineral metabolism or reproductive cycling and hormones in female rhesus monkeys. J Nutr 131: 820-827, 2001.

27. Mardon J, Trzeciakiewicz A, Habauzit V, Davicco MJ Lebecque P, Mercier S, Tressol JC, Horcajada MN, Demigné C and Coxam V: Dietary protein supplementation increases peak bone mass acquisition in energy-restricted growing rats. Pediatr Res 66: 513-518, 2009.
28. Wronski TJ, Cintrón M, Doherty AL and Dann LM: Estrogen treatment prevents osteopenia and depresses bone turnover in ovariectomized rats. Endocrinology 123: 681-686, 1988

29. Coxam V, Bowman BM, Mecham M, Roth CM, Miller MA and Miller SC: Effects of dihydrotestosterone alone and combined with estrogen on bone mineral density, bone growth, and formation rates in ovariectomized rats. Bone 19: 107-114, 1996.

30. Windahl SH, Vidal O, Andersson G, Gustafsson JA and Ohlsson C: Increased cortical bone mineral content but unchanged trabecular bone mineral density in female ERbeta(-/-) mice. J Clin Invest 104: 895-901, 1999.

31. Manolagas SC, Almeida M and Jilka RL: Gonadal steroids. In: Primer on the Metabolic Bone Diseases and disorders of Mineral Metabolism. John Wiley \& Sons, Inc., Hoboken, NJ, pp195-207, 2013.

32. Vinel A, Hay E, Valera MC, Buscato M, Adlanmerini M, Guillaume M, Cohen-Solal M, Ohlsson C, Lenfant F, Arnal JF, et al: Role of ER $\alpha$ in the effect of estradiol on cancellous and cortical femoral bone in growing female mice. Endocrinology 157: 2533-2544, 2016.

33. Oseni T, Patel R, Pyle J and Jordan VC: Selective estrogen receptor modulators and phytoestrogens. Planta Med 74: 1656-1665, 2008.

34. Geary N, Asarian L, Korach KS, Pfaff DW and Ogawa S: Deficits in E2-dependent control of feeding, weight gain, and cholecystokinin satiation in ER-alpha null mice. Endocrinology 142: 4751-4757, 2001.

35. Van Pelt RE, Gavin KM and Kohrt WM: Regulation of body composition and bioenergetics by estrogens. Endocrinol Metab Clin North Am 44: 663-676, 2015.

36. Yepuru M, Eswaraka J, Kearbey JD, Barrett CM, Raghow S, Veverka KA, Miller DD, Dalton JT and Narayanan R: Estrogen receptor- $\{\beta\}$-selective ligands alleviate high-fat diet- and ovariectomy-induced obesity in mice. J Biol Chem 285: 31292-31303, 2010.

37. Weigt C, Hertrampf T, Zoth N, Fritzemeier KH and Diel P: Impact of estradiol, ER subtype specific agonists and genistein on energy homeostasis in a rat model of nutrition induced obesity. Mol Cell Endocrinol 351: 227-238, 2012.

38. Chiechi LM, Secreto G, D'Amore M, Fanelli M, Venturelli E, Cantatore F, Valerio T, Laselva G and Loizzi P: Efficacy of a soy rich diet in preventing postmenopausal osteoporosis: The Menfis randomized trial. Maturitas 42: 295-300, 2002. 